\title{
O PADRÃO FRASAL \\ [TREM + ADJETIVO] \\ SOB A PERSPECTIVA \\ DA GRAMÁTICA \\ DE CONSTRUÇÕES
}

\section{LA SECUENCIA FRASEOLÓGICA [TREM + ADJETIVO] DESDE LA PERSPECTIVA DE LA GRAMÁTICA DE CONSTRUCCIONES}

\author{
THE PHRASAL PATTERN [TREM + ADJECTIVE] FROM THE PERSPECTIVE OF THE \\ CONSTRUCTION GRAMMAR
}

\author{
Aléxia Teles Duchowny* \\ Paola Santos Lima Soares**
}

Universidade Federal de Minas Gerais

RESUMO: Este artigo examina o padrão frasal [trem + adjetivo], em 1000 ocorrências de amostras do Twitter, objetivando averiguar, sob a ótica da Gramática de Construções e do Modelo de Língua Baseado no Uso e da Gramaticalização, se este padrão se trata de uma construção do português brasileiro, aplicável não só a objetos, mas também a pessoas. Foram encontradas evidências de que, no uso informal, o padrão frasal [trem + adjetivo] faz referência a pessoas em contextos em que não há depreciação do referente, como costuma ocorrer com o nome trem isoladamente, o que atesta a hipótese de que se trata de uma construção do português brasileiro.

PALAVRAS-CHAVE: Gramática de Construções. Teoria do modelo de língua baseado no uso. Termo trem. Nomes gerais. Português do Brasil.

RESUMEN: Este artículo examina la secuencia fraseológica [trem + adjetivo] en 1000 ocurrencias de muestras en Twitter, con el objetivo de determinar - desde la perspectiva de la Gramática de Construcciones, del Modelo de Lengua Basado en el Uso y de la Gramaticalización - si esta secuencia se trata de una construcción del portugués brasileño, aplicable no solo a objetos, sino también a personas. Se encontró evidencia de que, en el uso informal, la secuencia fraseológica [trem + adjetivo] se refiere a personas en contextos donde no hay una depreciación del referente, como suele suceder con el nombre de trem solo, lo que confirma la hipótesis de que se trata de una construcción del portugués brasileño.

\footnotetext{
* Doutora em Estudos Linguísticos pela Faculdade de Letras da Universidade Federal de Minas Gerais. Professora associadada Área de Estudos Diacrônicos. E-mail: alexiateles@letras.ufmg.br.

** Graduada em Letras pela Faculdade de Letras da Universidade Federal de Minas Gerais. Mestranda do Programa de Pós-Graduaçãoem Estudos Linguísticos, combolsadaCAPES. E-mail:paolasantoslimasoares@gmail.com.
} 
PALABRAS CLAVE: Gramática de construcciones. Teoría del modelo de lengua basado en el uso. Palabra trem. Sustantivos generales. Portugués brasileño.

ABSTRACT: This paper examines the phrasal pattern [TREM + adjective], in 1000 occurrences of Twitter samples, aiming to ascertain - from the perspective of the Construction Grammar and the Language Based Model of Use and Grammaticalization - if this pattern is a construction of Brazilian Portuguese, applicable not only to objects, but also to people. Evidence was found that, in informal usage, the phrasal pattern [TREM + adjective] refers to people in contexts where there is no depreciation of the referent, as usually occurs with the name train alone, which attests to the hypothesis that it is of a Brazilian Portuguese construction.

KEYWORDS: Construction Grammar. Theory of the language model based on the use. word trem. general nouns. Brazilian Portuguese.

\section{CONSIDERAÇÕES INICIAIS}

Quando não se deseja, não convém ou não é possível especificar algo por meio do substantivo que o designa ou de um pronome, há a opção de referir-se a ele utilizando nomes gerais (MIHATSCH, 2006). No português contemporâneo, os itens mais comuns pertencentes a essa classe são coisa, trem, negócio e pessoa. Esses nomes formam um conjunto de substantivos que, de acordo com Halliday e Hasan (1995 [1976]), aproximam-se dos pronomes, pois são itens com alto grau de generalização e, por isso, podem ser associados a entidades distintas. Tais nomes podem ser agrupados levando-se em consideração traços vagos como:

a) people, person, man, woman, child, boy, girl [humano];

b) creature [animado não humano];

c) thing, object [inanimado concreto contável];

d) stuff [inanimado concreto não contável];

e) business, affair, matter [inanimado abstrato];

f) move [ação];

g) place [lugar];

h) question, idea [fato] (HALLIDAY; HASAN, 1995 [1976], p. 274).

Objeto de estudo deste artigo, o nome geral trem foi evidenciado por Amaral (2014), que concluiu que esse substantivo integra o grupo dos nomes gerais que não possuem o traço [+humano] e é empregado preferencialmente em retomadas anafóricas cujo referente é uma entidade concreta inanimada, sobre a qual se faz uma avaliação negativa. Em relação à referência a pessoas, Amaral e Ramos (2014) chegaram à conclusão de que, com essa finalidade, esse item é usado raramente e de modo predominantemente pejorativo. Ou seja, é usado em contextos em que há a intenção do falante em rebaixar o seu referente à condição de objeto, destituindo-lhe da sua humanidade.

Contudo, não é incomum, na linguagem oral coloquial, serem direcionadas tanto a objetos quanto a pessoas expressões que contêm trem com conotação positiva, como “Que trem fofo!" e "Êhh trem bão!". Essas expressões são frases exclamativas que têm em comum o padrão frasal [trem + adjetivo]. Esse fato nos leva à hipótese de que o uso frequente desse padrão teria provocado a unificação dos elementos que o compõem, fazendo com que se constituísse uma construção. Em seguida, ter-se-ia desencadeado um processo de gramaticalização, que, ao expandir os contextos de uso do padrão [trem+ adjetivo], possibilitou a referência a humanos, tanto em situações negativas como positivas.

Tendo em vista o exposto, o objetivo deste artigo é não só atestar a ocorrência de contextos em que trem possa ser empregado, tanto de modo positivo quanto negativo na referência a humanos, quando inserido no padrão frasal [trem + adjetivo], mas também utilizar esses dados para analisar o padrão frasal [trem + adjetivo] à luz da Teoria da Gramática de Construções, para verificar se esse padrão é uma construção do português. Nesse sentido, o artigo será subdivido nas seguintes partes: inicialmente, serão retomados alguns trabalhos sobre o comportamento linguístico do nome geral trem e será apresentado o referencial teórico sobre a Teoria da 
Gramática de Construções e da gramaticalização. Em seguida, virá a metodologia com a análise dos dados e, posteriormente, as considerações finais, com os resultados do trabalho.

\section{ASPECTOS TEÓRICOS}

Segundo Halliday e Hasan (1995 [1976]), um nome geral é um caso limítrofe entre um elemento lexical (membro de uma classe aberta) e um elemento pronominal (membro de um sistema fechado). Essas categorias se distinguem, de acordo com Schmid (2000), segundo a capacidade de caracterização e a capacidade de estabelecer ligações coesivas. Enquanto os elementos lexicais podem caracterizar mais detalhadamente aquilo que designam, os pronomes não são capazes de especificar particularidades das entidades a que se referem, consequentemente, estabelecem com elas relações instáveis e temporárias. Em função disso, os pronomes se sobressaem quanto ao potencial coesivo, pois, por não designarem um objeto em especifico, podem retomar elementos heterogêneos. Nesse sentido, os nomes gerais aproximam-se dos pronomes por seu potencial em retomar elementos distintos, já que esses substantivos detêm traços vagos com capacidade mínima de caracterização.

Sob perspectivas teóricas diversas, outros estudos foram realizados em relação aos nomes gerais. Por exemplo, Mahlberg (2005) buscou encontrar evidências de que os nomes gerais constituem uma classe à parte, valendo-se da abordagem da linguística de corpus. Oliveira (2006), analisando nomes que fazem referências vagas e têm participação mínima no significado de construções que obedecem à fórmula nome + adjetivo denominal, buscou encontrar critérios para delimitar o conjunto dos nomes gerais, ou como os chamou, substantivos-suporte, que pudessem ser atestados com métodos computacionais.

Amaral e Ramos (2014) relatam que o desenvolvimento desses itens em elementos anafóricos deu-se a partir de um processo de gramaticalização. Originalmente, esses itens eram específicos como os substantivos prototípicos, mas foram passando por processos de perda semântica e se tornando vagos, até chegar ao ponto de poderem retomar objetos com características distintas.

Mais especificamente sobre o item trem, nome geral que integra o padrão frasal analisado neste trabalho, [trem + adjetivo], destacam-se as análises de Ramos (2013) e de Amaral (2014). Ramos (2013), ao analisar o percurso histórico do nome geral trem, constatou a sua vinculação inicial à ideia de pertences, ou até de pessoas, que acompanham alguém em uma viagem. Posteriormente, o termo teria perdido a capacidade de se referir a pessoas e teria passado a designar a própria locomotiva e a fazer referência a qualquer objeto, não necessariamente àqueles que se levam em uma viagem. Essas conclusões se mantêm no estudo sincrônico realizado por Amaral (2014), que verifica que trem possui o traço [-humano] e, quando é usado para designar pessoas, tem como sinônimo traste.

Corroborando esta tese, as acepções que se encontram no dicionário Aulete Digital (AULETE, 2018) em relação ao uso do nome trem na referência a humanos são negativas: "pessoa ou coisa inútil" e "pessoa ou coisa sem valor ou utilidade". Verifica-se também que trem não apresenta marcas de plural quando empregado como nome geral e é geralmente antecedido por demonstrativos. Ele é usado principalmente como elemento anafórico para retomar entidades concretas avaliadas pelo falante como sem valor ou negativas.

Como o objetivo neste artigo é atestar a existência de expressões tanto com conotação positiva quanto negativa em que trem, incluído no padrão frasal [trem + adjetivo], refira-se a pessoas, à luz dos pressupostos da Gramática de Construções, averiguandose se essas expressões seriam construções do português brasileiro que teriam passado por um processo de gramaticalização, aumentando a abrangência no que se refere à capacidade de referenciação, faz-se necessário retomar algumas considerações sobre a Teoria da Gramática de Construções (GOLDBERG, 1995) e da Gramaticalização (HEINE, 2003).

Em relação à Teoria da Gramática de Construções, é importante ressaltar o que preconiza Goldberg (1995). Segundo a autora, construção é uma unidade linguística, que se caracteriza pelo pareamento entre a estrutura funcional (semântica, pragmática ou discursivo-funcional) e a estrutura formal (sintática, fonológica ou morfológica). Isto é, o sentido atrelado a uma construção advém da expressão como um todo e não a partir da soma dos significados dos elementos que a compõem. Desta forma, "C é uma 
construção, se e somente se $\mathrm{C}$ se constitui em um pareamento de forma e significado, de tal maneira que alguns aspectos da forma, ou alguns aspectos do significado, não são estritamente previsíveis a partir de partes componentes de $\mathrm{C}$ ou de outras construções previamente estabelecidas." '(GOLDBERG, 1995, p. 4, tradução nossa).

Nesse sentido, o significado de uma construção independe da soma dos significados dos elementos que dela fazem parte, podendo ser mais ou menos composicional em função da possibilidade de decodificar-se o seu significado a partir da soma dos elementos lexicais e gramaticais que a compõem. Quanto menor a transparência do significado de uma expressão, menos composicional ela é, consequentemente, quanto maior a correspondência entre forma e sentido, mais composicional torna-se a construção (TRAUGOTT; TROUSDALE, 2013).

Construções podem passar por um processo de gramaticalização, expandindo os seus contextos de uso. Segundo Lehmann (1992), a gramaticalização não acomete apenas uma palavra ou morfema, ela pode ocorrer em uma construção como um todo. Heine e Rech (1984) definem a gramaticalização como um processo de mudança em que as unidades linguísticas se tornam semanticamente menos complexas, sintaticamente mais fixas e mais reduzidas ao perderem substância fonética.

Heine (2003) apresenta alguns mecanismos constituintes do processo de gramaticalização: a dessemantização, que consiste na expansão dos contextos de uso de um item após passar por um esvaziamento da sua semântica lexical; a descategorização, que ocorre quando o item assume características de outra categoria, passando a ocupar posições de outras categorias; a cliticização, quando o item torna-se um operador, uma forma dependente; e, por fim, a erosão, quando ocorre perda fonética no item.

Nesse sentido, faz-se necessário verificar se o padrão [trem + adjetivo] apresenta características que o possam definir como uma construção. Para isso, as seguintes questões deverão ser respondidas: [trem + adjetivo] se constitui em um pareamento de forma e significado? Há indícios de que esse padrão tenha passado por um processo de gramaticalização, expandindo os seus contextos de uso?

\section{METODOLOGIA}

O quadro teórico do modelo de língua baseado no uso (GOLDBERG, 1985; BYBEE, 2013) tem como premissa básica a ideia de que a interação afeta a linguagem, isto é, as experiências concretas com a linguagem moldam a representação cognitiva da própria linguagem. Com base nisso, Bybee (2013) discorre sobre os efeitos da frequência de uso de sequências de unidades. Para ela, é a repetição que provoca a convencionalização de sequências e, consequentemente, faz com que elementos que sempre ocorram juntos sejam acessados juntos, como uma unidade. Outro efeito associado à alta frequência de uso é que a repetição de sequências pode desencadear mudanças, no que tange ao nível fonológico e ao significado, ao mesmo tempo em que favorece a preservação da estrutura no nível morfossintático.

Em relação ao fenômeno analisado neste trabalho, a hipótese é a de que o padrão frasal [trem + adjetivo] tenha se consolidado a partir do uso frequente e tenha se tornado menos composicional com a ampliação de seus contextos de uso. Acredita-se que a expressão tenha se gramaticalizado como um todo, o que permitiu novas instanciações, ou seja, permitiu que o padrão [trem + adjetivo] passasse a aceitar a referência a humanos sem que houvesse necessariamente a intenção de associar o outro a um objeto.

Em busca de dados que corroborassem esta tese, foi empregado como corpus o Twitter, uma rede social amplamente utilizada na internet. Essa escolha foi motivada pelo fato de que os tweets, textos de até 140 caracteres, aproximam-se do discurso oral informal, pois recria-se um ambiente de interação, principalmente entre jovens, em que prevalece a fala espontânea pouco monitorada. Ademais, acredita-se que o padrão frasal [trem + adjetivo] seja mais propício em registros informais.

\footnotetext{
${ }^{1}$ Do original: "C is a construction if, $\mathrm{C}$ is a form-meaning pair such that some aspect of $\mathrm{F}$, or some aspect of $\mathrm{S}$, is not strictly predictable from C's component parts or from other previously established constructions.”
} 
Para testar se o uso de trem dissociado da noção de objeto na referência a pessoas advém do padrão frasal [trem + adjetivo] ou da gramaticalização do item trem isoladamente, analisaram-se 1000 contextos extraídos do Twitter. Inicialmente, buscaram-se separadamente ocorrências em que trem faz referência a humanos quando inserido no padrão [trem + adjetivo], em frases predicativas e exclamativas, afirmativas e negativas, para verificar se esse padrão é usado tanto em situações em que há uma avaliação positiva quanto negativa do referente. Isso foi possível porque, com a ferramenta de busca do Twitter, pode-se não só procurar por palavras, mas também por expressões. Dessa forma, foram testados os seguintes adjetivos: bom, bão, fofo, bonito, maravilhoso e lindo e optou-se por restringir a análise às 100 primeiras ocorrências de expressões com trem acompanhado por cada um desses adjetivos, totalizando 600 ocorrências, e optou-se por quantificá-las para atestar que as ocorrências encontradas não são meros exemplos isolados e acidentais. Também foram coletadas algumas amostras de ocorrências em que o padrão [trem + adjetivo negativo] foi direcionado a pessoas, em menor número, apenas para exemplificar, pois a possibilidade de essas ocorrências ocorrerem era previsível devido ao aspecto pejorativo de trem quando utilizado para se referir a pessoas, já apontado por Amaral (2014).

Em seguida, buscaram-se as ocorrências em que o item trem aparece não acompanhado de adjetivo em seus contextos sintáticos mais comuns, que, de acordo com Amaral (2013), são os seguintes: trem antecedido por esse/s, aquele/s, o/os, um/uns. O intuito era verificar se trem é empregado isoladamente de modo anafórico na referência a humanos em situações em que a finalidade não seja de depreciação do referente, isto é, em situações em que trem seja um elemento anafórico neutro. Optou-se, também, por restringir a análise aos determinantes no singular e às 100 primeiras ocorrências de cada padrão sintático, totalizando 400 ocorrências.

Todos esses dados foram coletados no ano de 2018, por meio do Twitter. As realizações no português brasileiro do padrão [trem + adjetivo] foram os seguintes:

\begin{tabular}{|c|c|c|c|c|}
\hline Expressão & Exemplo & [+humano] & [-humano] & Total \\
\hline Trem + bom & $\begin{array}{l}\text { (1) "Mulher é um trem bom demais, eu sou } \\
\text { apaixonado" }\end{array}$ & 14 & 86 & 100 \\
\hline Trem + bão & $\begin{array}{l}\text { (2) "Tal da mulher faz a gente fazer de tudo } \\
\text { né rapz... aoo trem bao" }\end{array}$ & 4 & 96 & 100 \\
\hline Trem $+f_{o} f_{o}$ & (3) "Trem mais fofo do tio" & 28 & 72 & 100 \\
\hline Trem + bonito & $\begin{array}{l}\text { (4) "Colombiano é um trem bonito ou eu só } \\
\text { dei sorte do meu amigo ser??" }\end{array}$ & 35 & 65 & 100 \\
\hline $\begin{array}{c}\text { Trem }+ \\
\text { maravilhoso }\end{array}$ & (5) "mae é um trem maravilhoso demais ne" & 25 & 76 & 100 \\
\hline Trem + lindo & $\begin{array}{c}\text { (6) "eu te amo tanto que chega a doer feliz } \\
\text { dia dos namorados trem lindo da minha } \\
\text { vida" }\end{array}$ & 68 & 32 & 100 \\
\hline
\end{tabular}

Tabela 1: Realizações do padrão [trem + adjetivo] com conotação positiva

Fonte: a autoria

Vale dizer, como já mencionado, que também foram encontradas ocorrências no Twitter em que o padrão [trem + adjetivo] composto de trem seguido de um adjetivo negativo foi usado para se referir de modo pejorativo a humanos. No entanto, optou-se por não quantificar as ocorrências nesse caso, pois essas expressões seriam previsíveis e não poderiam ser empregadas para corroborar a tese aqui defendida. Alguns exemplos são os seguintes, todos do Twitter: 
(7) “GENTE, TO CHEIO DE SAUDADE DA MINHA NAMORADA, VONTADE DE VER AQUELE TREM CHATO... VOCÊS NÃO IMAGINAM”.

(8) “eu queria TANTO não gostar de homem, ô trem ridículo”.

(9) “só pra constar q era pra eu estar arrumadinha no role e eu tava um trem feio desse".

Em relação ao item trem iniciado por determinante sem a presença de adjetivo, os dados obtidos foram os seguintes:

\begin{tabular}{|c|c|c|c|c|}
\hline Determinante + trem & $\begin{array}{l}\text { Todas as ocorrências encontradas com traço } \\
\text { [+humano }]\end{array}$ & [+humano] & [-humano] & Total \\
\hline Aquele + trem & $\begin{array}{l}\text { (10) "Vou excluir aquele trem, eu vou fazer merda de } \\
\text { novo se continuar com ele, sangue de Jesus." } \\
\text { (11) "Homem é aquele trem ne, } 3 \text { dias atras ta atras de } \\
\text { vc e dps aparece do nada namora" } \\
\text { (12) “aquele trem tenta agradar minha família ainda, } \\
\text { que nojo" } \\
\text { (13) "fiquei com o estojo do paixão mano, quero ver } \\
\text { como aquele trem vai estudar kkkkkkkkkkkkkkkj" } \\
\text { (14) "qq é o fim dessa vontade de beijar aquele trem } \\
\text { de novo" } \\
\text { (15) "Te avisei que aquele trem não prestava, amiga” } \\
\text { (16) “a hamylle foi chamar a mae dela de feia karol e } \\
\text { disse que era por isso q saiu aquele trem" } \\
\text { (17) “A ridícula da Letícia podia me responder né... } \\
\text { deve ta dormindo aquele trem" }\end{array}$ & 8 & 92 & 100 \\
\hline Esse + trem & $\begin{array}{l}\text { (18) "Nada abala esse trem aqui" } \\
\text { (19) “quem q esse trem pensa qé ta é doido" } \\
\text { (20) "sonhoooooooo esse trem me notar" } \\
\text { (21) "Eu fico triste quando olho minhas fotos de } 2 / 3 \\
\text { anos atrás, eu era muito bonito, hoje virei esse trem" }\end{array}$ & 4 & 96 & 100 \\
\hline$O+$ trem & - & 0 & 100 & 100 \\
\hline$U m+$ trem & - & 0 & 100 & 100 \\
\hline
\end{tabular}

Tabela 2: Realizações do item trem iniciado por determinante sem a presença de adjetivo

Fonte: a autoria 
Enfim, os dados atestam que o padrão [trem + adjetivo] é utilizado com combinações diversas para se referir a pessoas, em circunstâncias em que a avaliação do referente é tanto positiva quanto negativa. Foram encontradas 174 ocorrências, entre as 1000 analisadas, em que o padrão [trem + adjetivo positivo] faz referência a humanos. A maior parte dessas ocorrências concentra-se em expressões compostas por $[$ trem + lindo].

Já em relação às ocorrências em que trem aparece precedido de determinante sem a presença de adjetivos, foram encontradas 12 ocorrências em contextos em que trem faz referência a humanos, das 400 analisadas. Como é possível notar, apesar da presença de algumas ocorrências em que a avalição do referente é dúbia, na maior parte das ocorrências encontradas, em que trem não acompanha adjetivo, há a intenção de rebaixar o referente, equiparando-o à condição de objeto ao julgá-lo como uma pessoa sem valor. Esses dados corroboram a hipótese levantada neste artigo, pois verifica-se que, isoladamente, o item trem não é comumente utilizado de modo neutro para se referir a pessoas. Em contrapartida, quando incluído no padrão frasal [trem + adjetivo], o julgamento que se faz sobre o referente fica a cargo do adjetivo que o acompanha. Além disso, os dados evidenciam que o uso do padrão [trem + adjetivo] de modo positivo não é meramente acidental. São expressões que fazem parte da língua e são usadas com uma frequência considerável.

Portanto, verifica-se que existe uma discrepância entre as ocorrências em que trem aparece com e sem a presença de adjetivos, no que se refere à neutralidade do item na referência a pessoas. Isso corrobora a tese de que essa neutralidade é característica do padrão frasal [trem + adjetivo] e não se manifesta comumente quando o item trem apresenta-se isoladamente. Sem a presença de adjetivos, normalmente ele apresenta o traço [-humano] e é, portanto, usado preferencialmente para retomar objetos. Isso corrobora também a tese de que [trem + adjetivo] se constitui em um pareamento de forma e significado, pois não há uma correspondência direta entre o significado do substantivo trem e a função que ele desempenha ao retomar referentes com o traço [+humano].

Acredita-se que a combinação [trem + adjetivo] tenha, inicialmente, passado por um processo denominado chunking, que consiste no agrupamento de sequências de palavras após repetições recorrentes (BYBEE, 2010). Essa sequência de palavras teria passado a ser acessada como uma unidade. Uma construção cujos contextos de uso se expandiram. Esse fenômeno pode ser associado a um dos mecanismos da gramaticalização apontados por Heine (2003), a dessemantização, que se refere a casos em que elementos lexicais passam por um esvaziamento semântico. Pode-se inferir que o padrão frasal [trem + adjetivo] tenha passado por um processo de esvaziamento semântico porque um de seus elementos se tornou ainda mais vago do que se espera de um nome geral, passando a retomar indistintamente referentes com os traços [+/- humano]

\subsection{ANÁLISE DO PADRÃO [TREM + ADJETIVO] SEGUNDO CRITÉRIOS DE TRAUGOTT E TROUSDALE (2013)}

De acordo com Traugott e Trousdale (2013), uma construção se define a partir de características específicas. Toda construção possui um determinado nível de esquematicidade, de produtividade e de composicionalidade. Levando-se em conta esses apontamentos, faz-se necessário discutir e utilizar tais critérios para avaliar se o padrão [trem + adjetivo] pode ser considerado uma construção do português brasileiro.

\subsubsection{Esquematicidade}

Um esquema é uma abstração extraída de similaridades entre formações linguísticas. Isto é, uma série de configurações linguísticas similares pode compor uma rede construcional que obedece a um mesmo padrão de formação. Esse padrão de formação ou esquema pode ter os seus elementos rigidamente delimitados, pode ter elementos obrigatórios e lacunas a serem preenchidas conforme o contexto ou ainda conter apenas lacunas, que seguem um determinado padrão de preenchimento. Quanto mais especificados os elementos de uma construção, menor o grau de esquematicidade e vice-versa (TRAUGOTT; TROUSDALE, 2013).

Em relação ao fenômeno estudado aqui, verifica-se que se trata de um padrão parcialmente especificado ou parcialmente esquemático. O único elemento lexical fixo é o item trem, seguido obrigatoriamente de um adjetivo, cuja escolha obedece a razões 
circunstanciais. Os elementos que antecedem o item trem também são circunstanciais e não obedecem a uma regra. No entanto, nota-se que normalmente esse padrão se insere em uma frase exclamativa ou predicativa, como nos exemplos abaixo, do Twitter:

(22) “To é apaixonada... oh trem bonito"

(23) "o amor é um trem bonito dms drx"

\subsubsection{Produtividade}

A alta produtividade de uma construção se relaciona ao aumento da frequência type, que se refere à quantidade de itens lexicais que podem ocupar as lacunas de um padrão. Quanto maior a frequência type, maior a possibilidade de uma construção ocorrer com novas instanciações (BYBEE, 2013). Quando se pensa em construções com o item trem, vem logo à memória o adjetivo bom ou "bão". Segundo Amaral (2013), as construções trem bom e trem bão são tão frequentes que foram empregadas para denominar estabelecimentos comerciais, músicas, marcas de produtos alimentícios, entre outros. É provável que o esquema [trem + adjetivo] tenha se difundido a partir dessas construções e tenha passado a aceitar diversos outros adjetivos, mas isso precisaria ser atestado posteriormente. Mais presumível é a hipótese de que construções com trem tenham em um primeiro momento sido empregadas em referência a objetos e, posteriormente, com o aumento da sua frequência, tenham aumentado as suas instanciações, passando a se referir também a pessoas. Sintetizando as possibilidades de combinações diferentes do padrão [trem + adjetivo], atestadas nesse trabalho, veja-se o quadro abaixo:

\begin{tabular}{c|c} 
Elemento lexical fixo & Adjetivo \\
\cline { 2 - 2 } & bão \\
\cline { 2 - 2 } Trem & bom \\
\cline { 2 - 2 } & fonito \\
\cline { 2 - 2 } & lindo \\
\cline { 2 - 2 } & maravilho \\
\cline { 2 - 2 } & feio \\
\cline { 2 - 2 } Tabiculo
\end{tabular}

Tabela 3: Combinações encontradas que obedecem ao padrão [trem + adjetivo]

Fonte: a autoria

\subsubsection{Composicionalidade}

O grau de composicionalidade de uma construção se refere à correlação entre forma e função. A construção é mais composicional quando o seu significado é previsível a partir dos elementos que a compõem. Isto é, quando existe uma convergência entre a soma dos significados das unidades que a compõem e o significado da construção como um todo. Uma construção é pouco composicional quando não é possível depreender o seu significado a partir das unidades lexicais e gramaticais que a compõem. Em relação ao 
padrão [trem + adjetivo], acredita-se que ele seja mais composicional quando empregado na referência a objetos e menos composicional quando empregado na referência a pessoas.

Como se afirmou na análise dos dados, houve uma expansão dos contextos de uso do padrão [trem + adjetivo], o que se configura em um dos mecanismos que se inter-relacionam no processo de gramaticalização, a dessemantização, retomando Heine (2003). Expressões contendo o item trem, quando usadas para se referir a objetos, são facilmente decodificáveis, já que trem é empregado preferencialmente em retomadas anafóricas cujo referente é uma entidade concreta inanimada. No entanto, essa expressão se torna menos transparente ao ser direcionada a pessoas, principalmente quando a avaliação que se faz do referente é positiva, já que isoladamente trem costuma ser usado de modo pejorativo ao se referir a pessoas. Esse estranhamento pode ser verificado ao comparar-se exemplos como os seguintes do Twitter:

(24) "Homem é aquele trem ne, 3 dias atras ta atras de vc e dps aparece do nada namora"

(25) "Mulher é um trem bom demais, eu sou apaixonado"

\section{CONSIDERAÇÕES FINAIS}

Esse artigo objetivou analisar o padrão [trem + adjetivo] sob a perspectiva da Teoria da Gramática de Construções para verificar se há fundamentos para considerá-lo uma construção do português brasileiro. Considerando-se que uma construção se constitui em um pareamento de forma e significado (GOLDBERG, 1985), optou-se por evidenciar dados em que o padrão [trem + adjetivo] é usado em referência a pessoas, já que o item trem não possui o traço [+humano]. Nesse sentido, o uso na referência a pessoas de modo neutro do item trem inserido no padrão [trem + adjetivo] poderia evidenciar contextos de uso desse padrão em que não há transparência entre forma e função. Para reforçar a ideia de que essa neutralidade é característica do padrão [trem + adjetivo] e não advém do item trem particularmente, verificou-se se o item, quando não determinado por um adjetivo, é usado igualmente de modo neutro para se referir a pessoas. Além disso, para testar a hipótese de que esse padrão é uma construção do português, analisou-se o fenômeno sob critérios elencados por Traugott e Trousdale (2013): esquematicidade, composicionalidade e produtividade.

Foi encontrado um grande número de ocorrências em que o padrão frasal [trem + adjetivo] faz referência a pessoas em contextos em que o uso do item não tem como finalidade depreciar o referente, rebaixando-o à condição de objeto. Em contrapartida, sem a presença de adjetivo, foram poucas as ocorrências em que trem se referia a pessoas. E mesmo as poucas ocorrências encontradas evidenciam que trem não é usado de forma neutra quando não incluído no padrão [trem + adjetivo]. Na maior parte das ocorrências, depreende-se que trem tem como significado "pessoa sem valor" e pode ser substituído por traste. Em relação aos parâmetros utilizados por Traugott e Trousdale (2013), verificou-se que [trem + adjetivo] possui um grau de esquematicidade parcial, é dotado de certa produtividade, e é mais composicional quando utilizado na referência a objetos e menos composicional quando utilizado na referência a pessoas.

Tendo em vista o exposto, acredita-se que foram reunidas evidências suficientes para afirmar-se que o padrão [trem + adjetivo] é uma construção do português brasileiro. Mas, para que questões como a trajetória da gramaticalização dessa construção sejam clarificadas, faz-se necessário realizar novas investigações.

\section{REFERÊNCIAS}

AMARAL, E. T. R.; RAMOS, J. M. Nomes gerais no português brasileiro. Belo Horizonte: Faculdade de Letras da UFMG, 2014.

AMARAL, E. T. R. Análise de um nome geral na fala dos mineiros: para que serve esse trem? Revista Trama, v. 10, n. 20, p. 27-43, 2014. Disponível em: http://e-revista.unioeste.br/index.php/trama/article/view/9486. Acesso em: 11 out. 2018. 
BYBEE, J. Usage-based theory and exemplar representations of constructions. In: HOFFMANN, T.; TROUSDALE, G. (ed.). The Oxford Handbook of construction grammar. Oxford: Oxford University Press, 2013. p. 52-66.

GOLDBERG, A. E. Constructions: a construction grammar approach to argument structure. Chicago: The University of Chicago Press, 1995.

HALLIDAY, M. A. K.; HASAN, R. Cohesion in English. London/New York: Longman, 1995 [1976].

HEINE, B.; RECH, M. Grammatical categories in African languages. Hamburgo: Helmut Buske, 1984.

HEINE, B. Grammaticalization. In: JOSEPH, B.; JANDA, R. D. (ed.). The Handbook of Historical Linguistics. Oxford: Blackwell, 2003. p. 575-601.

OLIVEIRA, C. M. G. M. de. O substantivo-suporte: critérios operacionais de caracterização. 2006. 121 f. Tese (Doutorado em Estudos Linguísticos) - Faculdade de Letras. Pontifícia Universidade Católica do Rio de Janeiro, Rio de Janeiro, 2006. Disponível em: http://www.dominiopublico.gov.br/pesquisa/DetalheObraForm.do?select_action=\&co_obra=61768. Acesso em: 10 out. 2018 .

MAHLBERG, M. English general nouns. Amsterdam/Philadelphia: John Benjamins, 2005.

MIHATSCH, W. Kognitive Grundlagen lexikalischer Hierarchien untersucht am Beispiel des Französischen und Spanischen. Tübingen: Niemeyer, 2006.

RAMOS, J. M. O surgimento de um nome geral: a lexia trem no dialeto mineiro. In: RAMOS, J. M.; COELHO, S. M. Português brasileiro dialetal: temas gramaticais. Campinas: Mercado de Letras, 2013. p.137-147.

SCHMID, H. J. English abstract nouns as conceptual shells. Berlin; New York: Mouton de Gruyter, 2000.

TRAUGOTT, E. C.; TROUSDALE, G. G. Constructionalization and Constructional Change. Oxford University Press: Oxford, 2013.

TREM. In: AULETE Dicionário Digital. Rio de Janeiro: Lexicon Editora Digital. Disponível em: http://www.aulete.com.br/trem. Acesso em: 12 jun. 2018.

\section{()(1) $\circledast \circledast$}

